\title{
A Case of Idiopathic Hypothalamic Hypothyroidism
}

\author{
Yutaka Tanaka, MD, Hiroki SAwa, MD, Masaaki Inden, MD, \\ Yoshitane Kosaka, MD and Hideo Takezawa, MD
}

\begin{abstract}
The availability of thyrotropin releasing hormone (TRH) has made it possible to determine whether tropic hormone deficiency is caused by pituitary or hypothalamic dysfunction. A case of hypothalamic hypothyroidism was described in a 17 year old woman. This patient was admitted for the evaluation of hypothyroidism and secondary amenorrhea. Her $T_{3}$ and $T_{4}$ were decreased, with an undetectable level of base line thyrotropin. The TRH test revealed normal but delayed response of TSH. Her base line prolactin and its response to TRH were normal. Adenocorticotropic hormone (ACTH), cortisol, growth hormone $(\mathrm{GH})$, and urinary 17 -hydroxysteroids were also normal. ACTH response to metyrapone was normal. Evaluation of the pituitary-gonadal axis revealed a normal increase in both lutenizing hormone (LH) and follicle stimulating hormone (FSH) following the intravenous administration of lutenizing hormone releasing hormone (LHRH). These results suggest that she had hypothalamic hypothyroidism as an isolated disturbance in the hypothalamic-pituitary axis. A deficiency of TRH is probably caused by a disorder of hypothalamic function of unknown etiology since the extensive studies did not reveal any secondary causes. It is recommended that patients with amenorrhea and hypothyroidism be evaluated for possible hypothalamic hypothyroidism.
\end{abstract}

Key Words: Thyrotropin releasing hormone, Thyroid stimulating hormone, Secondary amenorrhea, Lutenizing hormone releasing hormone, Hypothalamic-pituitary axis.

With the availability of synthetic TRH it became possible to assess the site of lesion in patients with hypothyroidism secondary to pituitary or hypothalamic disease ${ }^{1), 2)}$. This differentiation can be made by the response of TSH to TRH. Pittman and his associates were the first to describe a case of hypothyroidism due to hypothalamic origin ${ }^{3)}$. The case was characterized by decreased thyroid hormones, and detectable serum thyrotropin (TSH) levels, with a normal response to TRH which occurred following a head injury. They suggested the term "hypothalamic hypothyroidism" for TRH deficiency as a cause of hypothyroidism. Since then similar cases have been reported. However, in most cases there are usually such secondary causes as trauma, tumor, irradiation, or stalk section ${ }^{4) \sim 7)}$. Further- more, TSH deficiency is usually observed as a part of multiple pituitary deficiencies ${ }^{8), 9)}$.

We report here a case of hypothalamic hypothyroidism of unknown etiology where TSH deficiency was an isolated phenomenon.

\section{CASE REPORT}

A 17 year-old high school girl, was referred to our medical service for the evaluation of hypothyroidism. She was born of an uncomplicated pregnancy and delivery, and her early growth and development were considered normal. She underwent menarche at the age of 12 but her menstrual cycle never became regular, and at the age of 14 she became completely amenorrheic.

In March 1979, she began to be easily fatigued and developed cold intolerance. At that time she was seen by her physician

From the First Department of Internal Medicine, Mie University School of Medicine

Received for publication March 12, 1981.

Reprints request to: Hiroki Sawa MD, The First Department of Internal Medicine, Mie University School of Medicine, 2-174 Edobashi, Tsu-shi, Mie-ken, 514 Japan. 
and the diagnosis of hypothyroidism was made. She was started on thyroid tablets with the gradual improvement of her symptoms. She continued to take the drug for several months but then there was no follow up. Three months before her admission to our hospital, she again noticed easy fatigability, cold intolerance and constipation, which became gradually worse. She gained $9 \mathrm{~kg}$ during the last several months. She also withdrew from many of her school activities. She was found to have decreased levels of thyroid hormones: $\mathrm{T}_{4}, 2.1 \mu \mathrm{g} / \mathrm{dl}$; TSH, less than $2 \mu \mathrm{u} / \mathrm{ml}$. She was referred to our hospital. There was no history of headache, visual difficulties, skin dryness or deeping of her voice. There was no history of head trauma. Her family history was unremarkable.

Physical examination revealed that she was tall and well developed but appeared inactive in general. Her height was $170 \mathrm{~cm}$ and weight, $64 \mathrm{~kg}$. Blood pressure was 110 $/ 50 \mathrm{mmHg}$, pulse, $44 / \mathrm{min}$, regular, and respiration, $16 / \mathrm{min}$. Her temperature was as low as $35.4^{\circ} \mathrm{C}$. Her skin and hair were of normal consistency. The movement of eyes was normal and funduscopic examination was within normal limits. Her visual fields were intact. The thyroid gland was palpable, but not enlarged. The cardiac examination revealed no abnormalities except for sinus bradycardia. The lungs were normal. There was no hepatosplenomegaly. Pelvic examination disclosed no abnormalities. The neurological examination revealed that deep tendon reflexes were generally diminished with no lateralization. There were no pathological reflexes. Results of the routine laboratory studies were normal, including a complete blood count, urinalysis, and blood chemistry. The skull series showed a normal sella turcica. A computed tomographic scan of the brain revealed no abnormalities.

\section{EVALUATION OF ENDOCRI- NOLOGICAL FUNCTION}

\section{METHODS}

Jap J Med Vol 20, No 3 (July 1981)
Measurement of thyroid function was based on radioimmunoassay (RIA) for serum $\mathrm{T}_{4}, \mathrm{~T}_{3}$, and thyroid stimulating hormone (TSH). (commercial kit, Dinavot or Daiichi radioisotope research laboratories). Normal ranges of $\mathrm{T}_{4}, \mathrm{~T}_{3}$ and $\mathrm{TSH}$ are $4.5-13.0 \mu \mathrm{g} / \mathrm{dl}$, $0.8-1.8 \mathrm{ng} / \mathrm{ml}$ and less than $8 \mu \mathrm{u} / \mathrm{ml}$, respectively. Plasma LH, FSH, prolactin, growth hormone and cortisol were measured by RIA (Special reference laboratory). 17-KS and 17-OHCS were measured by standard techniques. LHRH $(100 \mu \mathrm{g}$, Tanabe) was given intravenously as a bolus, and TRH $(500 \mu \mathrm{g}$, Tanabe) over 5 minutes. Blood samples were taken before and at 15, 30, 60, 90 and $120 \mathrm{~min}$ after the injection. The plasma was separated immediately and stored at $-20^{\circ} \mathrm{C}$ until assayed. ACTH reserve was tested after metyrapone $(2.0 \mathrm{~g}$, orally at 12:00 pm).

\section{RESULTS}

The basic values of endocrinological function are shown in Table 1. Both $\mathrm{T}_{4}$ and $\mathrm{T}_{3}$ were decreased with low TSH. To determine whether the abnormality is pituitary or hypothalamic, TRH and LHRH tests were performed. As shown in Figs. 1 and 2 , the TRH test was abnormal in which the response of TSH secretion was delayed. A TSH value was $12.5 \mu \mathrm{u} / \mathrm{ml}$ at $60 \mathrm{~min}$, which

Table 1. Summary of endocrine studies.

\begin{tabular}{|c|c|c|c|}
\hline$T_{3}$ & 93 & $\mathrm{ng} / \mathrm{dl}$ & $\begin{array}{l}\text { normal range } \\
(90-180)\end{array}$ \\
\hline$T_{4}$ & 5.4 & $\mu \mathrm{g} / \mathrm{d} \mathrm{l}$ & $(6.0-12.0)$ \\
\hline $\operatorname{Res} T_{3}$ & 0.95 & & $(0.87-1.13)$ \\
\hline TSH & 2.9 & $\mu \mathrm{U} / \mathrm{ml}$ & ( less than 8 ) \\
\hline Cortisol & 170 & $\mathrm{ng} / \mathrm{ml}$ & $(106 \pm 44)$ \\
\hline $11-\mathrm{OHCS}$ (serum) & 23.9 & $\mu \mathrm{g} / \mathrm{d} \mathrm{l}$ & $(7.0-23.0)$ \\
\hline ACTH & 10 & $\mathrm{pg} / \mathrm{ml}$ & $(10-100)$ \\
\hline 17-KS (urine) & 4.48 & $\mathrm{mg} /$ day & $(1.9-8.5)$ \\
\hline 17-OHCS (urine) & 3.36 & $\mathrm{mg} /$ day & $(5.0-11.5)$ \\
\hline GH & 1.30 & $\mathrm{ng} / \mathrm{ml}$ & ( less than 5 ) \\
\hline LH & 8.6 & $\mathrm{mIU} / \mathrm{ml}$ & \\
\hline FSH & 8.8 & $\mathrm{mIU} / \mathrm{m} 1$ & \\
\hline Prolactin & 5.5 & $\mathrm{ng} / \mathrm{ml}$ & $(3.0-8.0)$ \\
\hline
\end{tabular}


was greater than those obtained at 15 and $30 \mathrm{~min}$. However, prolactin response was normal. LH and FSH showed normal response to LHRH. ACTH reserve test was also normal (Fig. 3). These findings are consistent with diagnosis of isolated defect of hypothalamus-pituitary-thyroid axis.

Treatment was begun with desicated thyroid $20 \mathrm{mg}$ daily which was gradually increased. She improved clinically. The level of $\mathrm{T}_{4}$ increased to $7.3 \mu \mathrm{g} / \mathrm{ml}$ two weeks after the initiation of therapy. Three months later, she returned to her usual school activities and her menses did not resume until 3 months after thyroid replacement.
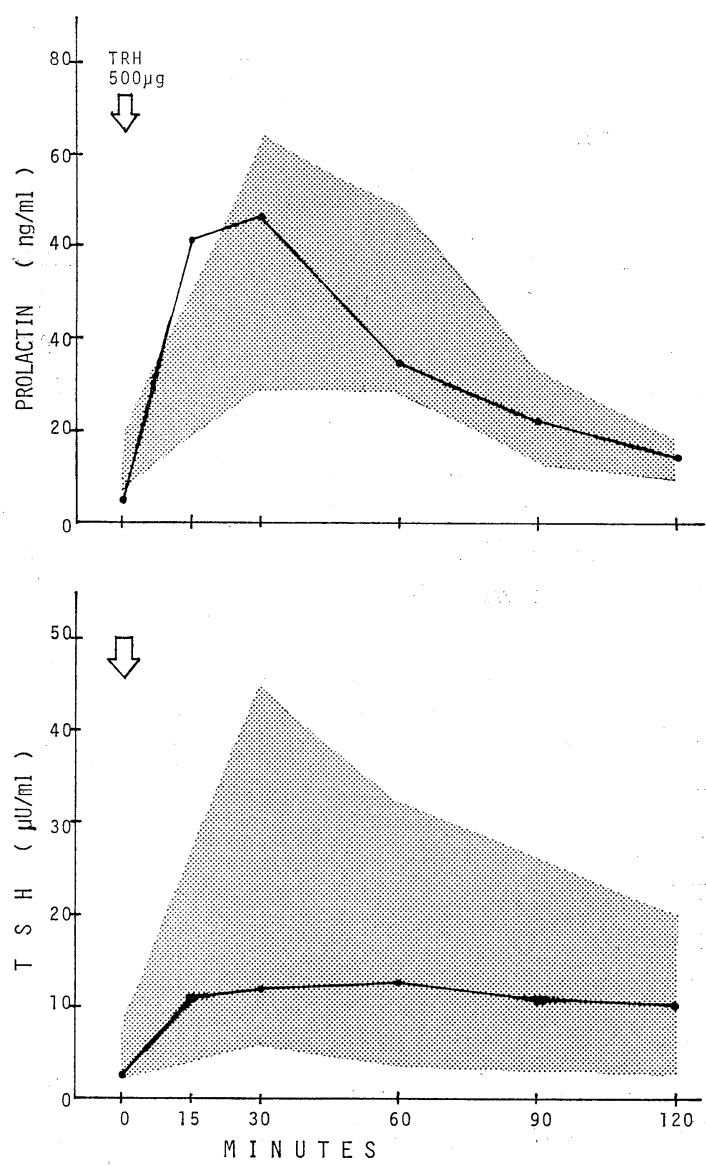

Fig. 1. Prolactin and TSH response to TRH administration. Prolactin response was normal following injection of TRH $(500 \mu \mathrm{g})$, and TSH response was normal but delayed. The shaded area indicates the normal range of response.
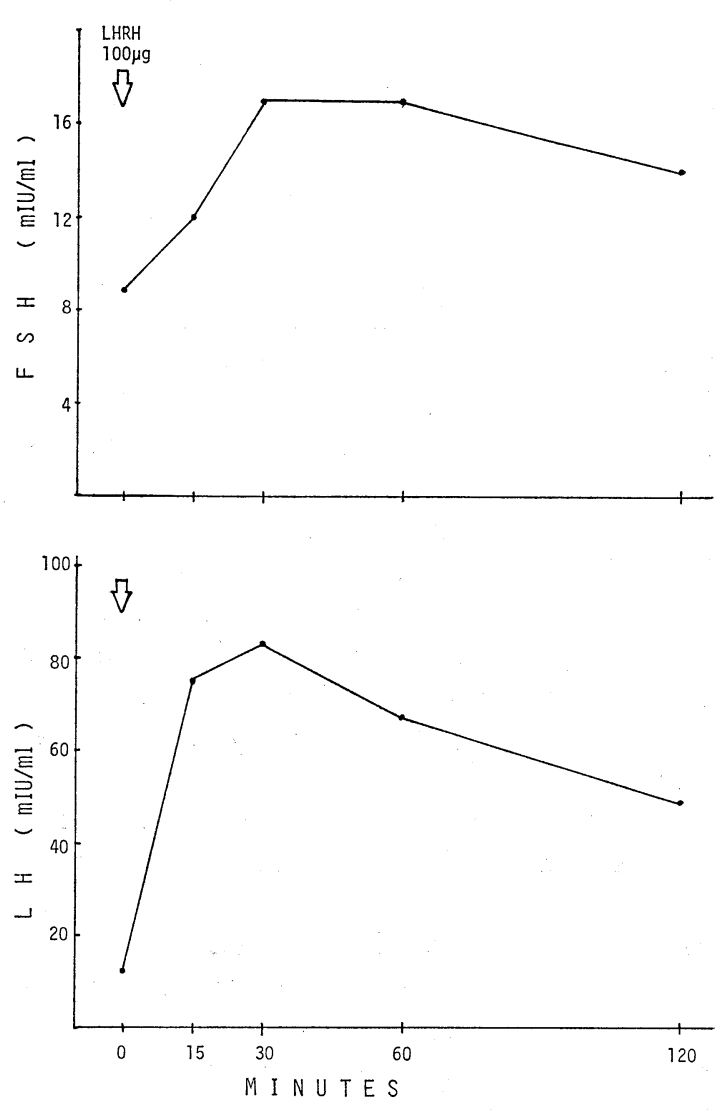

Fig. 2. FSH and $\mathrm{LH}$ response to LHRH administration. The intravenous administration of LHRH $(100 \mu \mathrm{g})$ caused normal response of both FSH and LH.

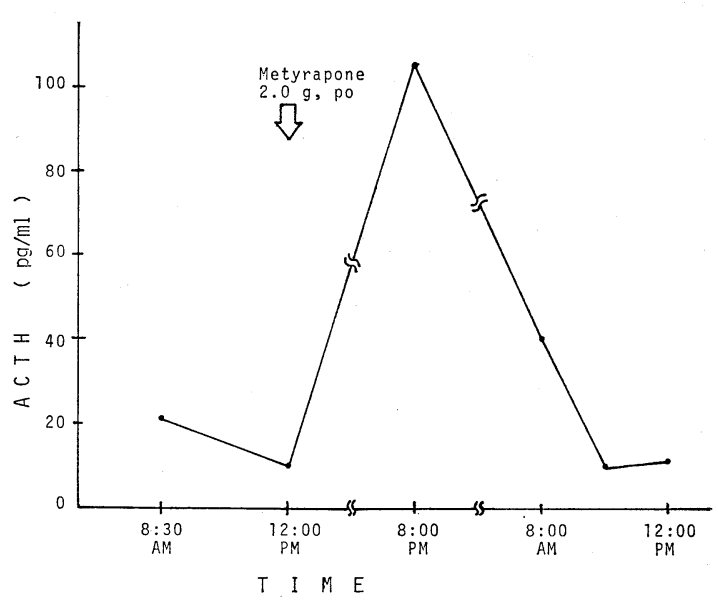

Fig. 3. ACTH reserve test. Metyroponse (2.0 g) was given orally at 12:00 pm. ACTH response was normal.

Jap J Med Vol 26, No 3 (July 1981) 


\section{DISCUSSION}

Our patient described here had hypothyroidism and decreased serum TSH level with delayed response to TRH. The response of prolactin levels to TRH was normal. These findings are all consistent with hypothalamic hypothyroidism. Furthermore, it is interesting to note that our patient seems to have abnormality of only the hypothalamic-pituitary-thyroid axis. As shown in Fig. 2, basal FSH and $\mathrm{LH}$ values were normal, as was the response to LHRH. The function of pituitary-adrenal axis was also normal.

The TSH response to TRH administration has been well studied in normal as well as in various endocrinological disorders ${ }^{10)-14)}$. Hall et al have studied TSH response after intravenous injection of $\mathrm{TRH}$ in 77 patients with diseases of the pituitary or hypothalamus $^{15)}$. Of 15 patients with various hypothalamic lesions, 8 had an impaired or absent response to $\mathrm{TRH} ; 3$ patients who responded normally to TRH had other evidence of hypothyroidism. A delayed response to $\mathrm{TRH}$, where the twenty-minute $\mathrm{TSH}$ level was less than the sixty-minute value, occurred in 13 of 15 in this group. They concluded that a normal TSH response to TRH, but a delayed response was characteristic of hypothalamic lesions. It appears that the TSH-producing cells of pituitary gland are intact, but certain time interval should elapse before the initiation of TSH synthesis.

As far as the etiology is concerned in our patient, it is probably idiopathic on the basis of normal skull X-ray and computed tomographic scan of the brain. Although, in the majority of cases, intracranial lesions could be found as the cause of hypothyroidism, idiopathic cases have rarely been reported ${ }^{4-6), 16)}$. A search of the English literature has revealed only five cases of idiopathic hypothalamic hypothyroidism which was an isolated phenomenon ${ }^{16), 17)}$. In Japan, two similar cases have been described ${ }^{18), 19)}$. Since an enzymatic mechanism of the syn- thesis of a hypophysiotropic hormone from aminoacid precursors was demonstrated in the hypothalamic tissue ${ }^{20)}$, it may be possible that the enzyme "TRH synthetase" is absent or deficient in some idiopathic cases.

Hypothyroidism has been associated with menorrhagia or irregular menses. However, amenorrhea is rare ${ }^{21)}$. Our patient exhibited secondary amenorrhea. Woolf has reported four women who had hypothyroidism due to hypothalamic insufficiency, although one patient did not show the typical pattern of TSH release to $\mathrm{TRH}^{16)}$. These four patients were similar to our patient in which the etiology was probably idiopathic and other hormonal systems except for pituitary-thyroid axis were normal. It is interesting to note that all four patients had secondary amenorrhea. It has been suggested that an acquired abnormality within the hypothalamus was a probable cause of amenorrhea in view of their normal LH and FSH response to exogenous LHRH administration.

The cause of amenorrhea is unclear. It is at least in part causally related to thyroid deficiency on the basis of normal values of FSH, LH and prolactin. It should be noted, however, that there is considerable evidence from both animal experiments and studies in hypothyroid patients that thyroid deficiency may lead directly to impairment in gonadotropin secretion ${ }^{22)-24)}$. The menstrual response to thyroid hormone replacement is variable. In all four patients described by Woolf, the menstruation did not occur until 4 to 6 months after beginning treatment. By contrast, Kramer et $\mathrm{al}^{17)}$ reported patients resumed menstrual cycle 2-3 months after treatment. In our patient, menses did not resume until 3 months after thyroid replacement.

Young women presenting secondary amenorrhea and hypothyroidism may have hypothalamic hypothyroidism. In such a clinical setting, TRH and LHRH tests are recommended.

ACKNOWLEDGFMENTS: We are indebted to Dr Satoru Sekoguchi for referring the patient described in this report. 


\section{REFERENCES}

1) Bøler J, Enzmann F, Folkers K, et al: The identity of chemical and hormonal properties of the thyrotropin releasing hormone and pyroglutamyl-histidyl-proline amide. Biochem Biophys Res Commun 37: 705, 1969.

2) Burgus R, Dunn TF, Desiderio D, et al: Structure moléculaire du facteur hypothalamique hypophysiotrope TRF d'origine: mise en évidence par spectrométrie de masse de la sequence PCA-His-Pro-NH ${ }^{2}$. CR Acad Sci (D) (Paris) $269: 1870,1969$.

3) Pittman JA, Haigler ED, Hershman JM, et al : Hypothalamic hypothyroidism. New Engl J Med 285 : 844, 1971.

4) Woolf PD, Jacobs LS, Donofrio R, et al : Secondary hypopituitarism : evidence for continuing regulation of hormone release. J Clin Endocrinol Metab 38: 71, 1974.

5) Tolis G, Goldstein M, Friesen HG: Functional evaluation of prolactin secretion in patients with hypothalamic-pituitary disorders. $\mathrm{J}$ Clin Invest 52 : 783, 1973.

6) Martin LG, Martul P, Connor TB, et al : Hypothalamic origin of idiopathic hypopituitarism. Metabolism 21: 143, 1972.

7) Larkins RG, Martin FIR: Hypopituitarism after extracranial irradiation: evidence for hypothalamic origin. Brit Med J 1: 152, 1973.

8) Mortimer $\mathrm{CH}$, Besser GM, McNeilly AS, et al: Luteinizing hormone and follicle stimulating hormone-releasing hormone test in patients with hypothalamic-pituitary-gonadal dysfunction. Brit Med J 4: 73, 1973.

9) Strauss JH, Yen SSC, Benirschke K, et al: Hypothalamic hypopituitarism in an adolescent girl: assessment by a direct functional test of the adenohypophysis. J Clin Endocrinol Metab 39: 639, 1974.

10) Gual G, Kastin AJ, Schally AV: Clinical experience with hypothalamic releasing hormones. 1. Thyrotropin-releasing hormone. Rec Prog Horm Res 28 : 173, 1972.

11) Coston $\mathrm{BH}$, Grumbach MM, Kaplan SL: Effect of thyrotropinreleasing factor on serum thyroid-stimulating hormone. An approach to distinguishing hypothalamic from pituitary forms of idiopathic hypopituitary dwarfism. J Clin Invest 50:2219, 1971.

12) Foley TP, Owings J, Hayfold JT, et al : Serum thyrotropin responses to synthetic thyrotropin-releasing hormone in normal chil- dren and hypopituitary patients. A new test to distinguish primary releasing hormones deficiency from primary pituitary hormone deficiency. J Clin Invest 51: 431, 1972.

13) Snyder PJ, Jacob LS, Ra bello MM: Diagnostic value thyrotropin-releasing hormone in pituitary and hypothalamic diseases. Assessment of thyrotropin and prolactin secretion in 100 patients. Ann Int Med 81: 751, 1974.

14) Patel YG, Burger HG: Serum thyrotropin (TSH) in pituitary and/or hypothalamic hypothyroidism : normal or elevated basal levels and paradoxical responses to thyrotropin-releasing hormone. J Clin Endocrinol Metab 37 : 190, 1973.

15) Hall R, Ormston BJ, Beser GM, et al: The thyrotropin-releasing hormone test in diseases of the pituitary and hypothalamus. Lancet 1: 759, 1972

16) Woolf PD: Hypothyroidism and amenorrhea due to hypothalamic inufficiency. A study in four young women. Am J Med 63 : 343, 1977.

17) Kramer MS, Kauschansky A, Genel M: Adolescent secondary amenorrhea: association with hypothalamic hypothyroidism. J Pediatrics $84: 300,1979$.

18) Yoshimoto S, Moridera $\mathrm{K}$, Miyamoto $\mathrm{Y}$, et al: Isolated TRH deficiency. Jap J Clin Med 32: 2405, 1974 (in Japanese)

19) Hara $Y$, Ishii J, Wakabayashi $T$ : A case of hypothalamic hypothyroidism. J Saitama Med School 5: 107, 1978 (in Japanese).

20) Mitnick M, Reichlin S: Enzymatic synthesis of thyrotropin-releasing hormone (TRH) by hypothalamic "TRH synthetase". Endocrinology $91: 1145,1972$.

21) Scott JG, Mussey E: Menstrual patterns in myxedema. Amer J Obstest Gynecol 90: 161, 1964.

22) Distiller LA, Sagel J, Morley JE: Assessment of pituitary gonadotropin reserve using luteinizing hormone- releasing hormone ( $\mathrm{LRH}$ ) in states of altered thyroid function. J Clin Endocrinol Metab 40: 512, 1975.

23) Bruni JF, Marshall S, Dibbet JA, et al : Effects of hyper- and hypothyroidism on serum $\mathrm{LH}$ and FSH levels in intact and gonadectomized male and female rats. Endocrinology $97: 558,1975$.

24) Dunn JD, Hess M, Johnson DG: Effects of thyroidectomy on rhythmic gonadotropin release. Proc Soc Exp Biol Med 151: 22, 1976. 